\title{
Predicting Technical Investors' Decisions in a Financial Market through Agent-Based Simulation
}

\author{
Yoshiki Kano ${ }^{1,2}$ Takao Terano ${ }^{1}$ \\ ${ }^{1}$ Tokyo Institute of Technology \\ ${ }^{2}$ Mitsubishi UFJ Asset Management
}

\begin{abstract}
We are developing an artificial stock market model with investor agents in order to analyze characteristics of a market price. In this paper, we analyze the effects of agent's reaction rate to technical indicators in a financial market. Intensive experiments have suggested that trend follow investor tends to change his reaction rate frequently to increase his wealth. Moreover, we could get positive return using proper technical indicators in a given artificial stock price path. Based on these results, we propose a simple price estimation method in a real financial market.
\end{abstract}

Keywords: artificial market, agent based model,

\section{Introduction}

In this paper we analyze characteristics of price changes in the market where a past price movement influences agents' evaluation of securities, and propose a price prediction method applied to these markets.

The main results in this paper are below. (1) We demonstrate that frequencies of changing reaction rate to technical indicators influence both a return of the "Trend follow investor" who predicts positive correlation to the past price movements and a that of the "Return reversal investor" who predicts retrogression to the past price average. (2) We find that an explanatory power of a trend follow technical indicator is high in some periods, and a return reversal indicator is in other periods. (3) We find that the indicator with high explanatory power is useful to predict future security prices.

After explaining the background of this research in section 2, we will explain our simulation model in section 3. Then, we will discuss simulation's results and their applications in section 4. Finally, we will conclude this paper in section 5 .

\section{Background of this research}

As shown by Shiller [1], the volatility in a stock market is large; we can hardly explain it only by the fundamental factors. LeBaron [2] insisted that investors' interaction is a cause of this high volatility. Besides investors' interaction, we need to consider an impact of non-rational investors' behavior, because DeLong et al. [3] illustrated there are chance for nonrational investors to survive long in the market. Arthur [4] and Brock et al. [5] analyzed these factors using artificial markets. There also are some papers in the behavioral finance field analyzing the impact of past price movement to the investors' decisions. For example, both "House money effect" [6] and "Escalation of commitment" [7] predict influences to investors' evaluation of securities through changes of their risk premium level. This may useful to understand some technical factors. Moreover, there are some models [8] which indicate high volatility of security price caused by changes of risk premium.

Following these researches, we use artificial market model based on Agent-based-modeling to analyze technical investment methods to predict future security price movements. In this paper, we build artificial market composed by only two types of investors in order to simplify the model. One of the objects of this simplification is to exclude complex factors in order to find a condition where both the Trend follow investor and the Return reversal investor can gain a positive return.

\section{Characteristics of the proposed model}

\subsection{Basic scheme}

In this paper, we build an artificial market composed of a Trend follow investor and a Return reversal investor trading only one type security to analyze influences of their behavior to a market price.

\subsection{Investors}


There is a difference between the Trend follow investor and the Return reversal investor. The Trend follow investor expects future appreciation under a bull market. On the other hand, the Return reversal investor believes mean retrogression movement and expects depreciation under a bull market. The expectation method used by the investors is below.

$$
\begin{aligned}
& \mathrm{E}\left(\mathrm{P}_{\mathrm{t}}\right)=\mathrm{P}_{\mathrm{t}-1}\left(1+\operatorname{React}_{\mathrm{T}}\left(\mathrm{P}_{\mathrm{t}-1} / \mathrm{P}_{\mathrm{t}-3}-1\right)+\varepsilon\right) \\
& \text { if an Agent is the trend follow investor } \\
& \mathrm{E}\left(\mathrm{P}_{\mathrm{t}}\right)=\mathrm{P}_{\mathrm{t}-1}\left(1-\operatorname{React}_{\mathrm{R}}\left(\mathrm{P}_{\mathrm{t}-1} / \operatorname{Avg}\left(\mathrm{P}_{\mathrm{t}-2}, \mathrm{P}_{\mathrm{t}-26}-1\right)+\varepsilon\right)\right. \\
& \text { if an Agent is the return-reversal investor } \\
& \mathrm{P}_{\mathrm{t}-1} \quad \text { : Price at } \mathrm{t}-1 ;
\end{aligned}
$$

$\mathrm{E}\left(\mathrm{P}_{\mathrm{t}}\right)$ : Expected Price at $\mathrm{t}$;

React $_{\mathrm{T}}$ : Reaction rate of a Trend follow investor;

React $_{R}$ : Reaction rate of a Return reversal investor;

$\operatorname{Avg}\left(\mathrm{P}_{\mathrm{t}-2}, \mathrm{P}_{\mathrm{t}-26}\right)$ : Average price from $\mathrm{t}-26$ to $\mathrm{t}-2$;

$\varepsilon \quad:$ random number in normal distribution (average:1, variance:0.01);

\subsection{Trade of security}

The investors above mentioned trade the only one security in the artificial market. As the number of the security in the market is only one, either the Trend follow investor or the Return reversal investor can hold it. Hence, if one investor wants to keep holding the security, the other investor could not purchase it. On the other hand, one investor could not sell the security, if the other investor wanted to purchase it.

\subsection{Pricing}

There are three types of pricing rules in the artificial market based on the investors' order situation. In the simplest case, the investors play a role of a seller and a buyer respectively. In this case, a trade would be settled if the ordered price of seller is lower than the buyer's one. Under this situation, the market price will be settled at the average ordered price of the seller and the buyer. The second case is that either the seller or the buyer is existed in the market. In this situation, any trade could not be settled and the market price will be decided by the ordered price of the investor. The third case is that neither the seller nor the buyer is existed. In this situation, the market price will be equal to the previous one. To sum up, the security price in the market is decided in the following way.

$$
\begin{aligned}
& P_{M(t)}=\left(P_{S}+P_{B}\right) / 2 \quad \text { if } V_{S}+V_{B}=0 \text { and } P_{S} \leqq P_{B} ; \\
& P_{M(t)}=P_{O} \quad \text { if } V_{S}+V_{B} \neq 0 ; \\
& P_{M(t)}=P_{M(t-1)} \quad \text { if } V_{S}=0 \text { and } V_{B}=0 ; \\
& P_{M(t)}: \text { Price in the Artificial Market at } t ; \\
& P_{S}: \text { Ordered price of seller; } \\
& P_{B}: \text { Ordered price of buyer; } \\
& P_{O}: \text { Ordered price of Investor; } \\
& V_{S}: \text { Volume of seller; }
\end{aligned}
$$

$\mathrm{V}_{\mathrm{B}}$ : Volume of buyer;

\subsection{Wealth}

An investor's wealth is the sum of money held and the security at the current value. At the initial of simulations, each investor has wealth worth to 1 . In other words, the investor holding no security has money worth to 1 and the investor holding a security has money worth to 1 minus the market value of the security.

\subsection{Reaction rate}

A reaction rate, React $_{T}$ or a React $_{R}$, reflects the investor's commitment to their technical indicator. If the reaction rate influenced the investors' long term return, we should set them at the proper range. Additionally, the update frequency of the investor's reaction rate should be set at the proper level, if the investors change their reaction rate.

\subsection{Procedure for changing the Reaction rate}

Each investor raises his reaction rate if the growth rate of his wealth were higher than that of other investor. This is based on our assumption that successful investor tends to respect their technical indicator, because he reinforce his self-confidence. The concrete methods of changing reaction rates are below.

$$
\begin{aligned}
& \operatorname{React}(\mathrm{t})=\operatorname{React}(\mathrm{t}-1)+\text { rnd } \quad \text { if } \Delta \mathrm{W}>\Delta \mathrm{W}_{\mathrm{M}} \\
& \operatorname{React}(\mathrm{t})=\operatorname{React}(\mathrm{t}-1) \text {-rnd } \Delta \mathrm{W}<\Delta \mathrm{W}_{\mathrm{M}} \\
& \operatorname{React}(\mathrm{t}): \text { the investor's reaction rate at period } \mathrm{t} \\
& \Delta \mathrm{W}: \text { change of the investor' } \mathrm{s} \text { wealth } \\
& \Delta \mathrm{W}_{\mathrm{M}}: \text { change of the all investors' wealth } \\
& \text { rnd : random value. }
\end{aligned}
$$

\section{Result of the simulation and applications}

\subsection{Condition of simulations}

In order to find relations between the investors' reaction rate and their wealth, we simulated under wide variety of reaction rates 1000 times respectively. The condition of the simulation is that the initial security price is 1.0 , the investors can borrow freely and simulation period is 260 .

\subsection{Result of the simulations}

As a result of the simulations, we found that a wealth of the Return reversal investor tended to large when 
the investors' reaction rates were low. Contrary, a wealth of the Trend follow investor tended to be large when the investors' reaction rates were high. Then, we deduce that the Return reversal investor tends to lower his reaction rate, and the Trend follow investor tends to higher it.

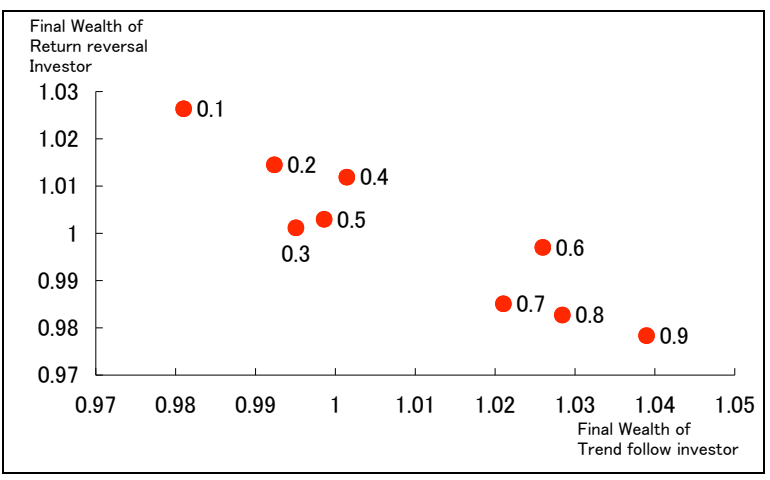

Fig. 1: Average Final Wealth of the investors.

Values labeled in the chart are the respective investors' frequencies of changing reaction rates.

\subsection{Characteristics of the market price}

Next, we analyzed characteristics of the market price created under the following four conditions. We will describe the frequency of changing the reaction rate as $F\left(f_{T}, f_{R}\right)$, under the condition that the $f_{T}$ is the frequency of changing Trend follower's reaction rate, and the $f_{R}$ is Return reversal's one.

$\mathrm{F}(0.9,0.1), \mathrm{F}(0.5,0.2), \mathrm{F}(0.5,0.5), \mathrm{F}(0.2,0.5)$

As a result of this analysis, we found that an explanation power of a trend follow technical indicator is high in a specific period and that of return reversal is high in other period.

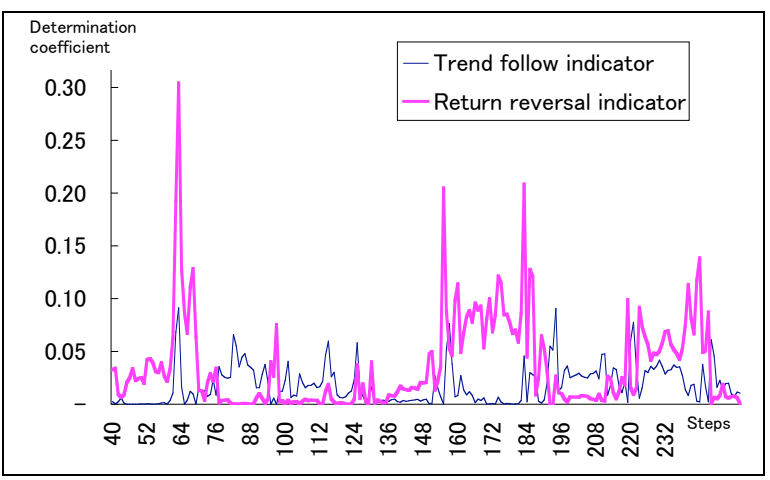

Fig. 2: Progress of determination coefficients' example.

\subsection{Behavior directed by the technical indicator}

We may not trade the security without the seller of the security, if we would like to do so using a technical indicator. What's more, because the new investor is added to the original investors, the price movement may be different from the original one. Contained with these problems, it is useful that we will identify whether the investor who has very small impact on the market price analyzing past price movement could get positive return. On this view point, we will verify whether the third investor could get positive return by the following steps. We suppose that the third investor knows the expectation methods of the other 2 investors in the artificial market.

Step 1. Security prices are created through the interaction of the Trend follow investor and the Return reversal investor in the artificial market.

Step 2. A Meta investor, the third investor, evaluates explanatory powers of both the trend follow indicator and the return reversal indicator to explain the future market price. The Meta investor uses the explanatory variables with the highest explanatory power to expect future price.

Step 3. The Meta investor could trade a security at any time he wants at the market price.

Using the above process, we found that the Meta investor could outperform market stock price about 80 times out of 100 simulations.

\subsection{Apply to the real market data}

In addition to verify the usefulness of the technical indicator to predict future market price through the artificial market, we have verified it through the real Japanese stock market data. We used the price index of the Tokyo Stock Exchange Market. We estimated the explanatory power of the time series explanatory data in order to predict future market price. Using the explanatory data with the highest explanatory power, we have predicted future market price. Repeating this process, we can gain stable positive return. Then, it is possible to say that technical investors may influence the real stock market price creation like the process cause in the artificial market of this paper.

\section{Conclusion}

In this paper, we built an artificial market to analyze its characteristics under the assumption that technical investors influence market prices. After the analysis, we found that both the Trend follow investor and the Return reversal investor could receive positive return in specific cases. We also found that trend follow indicators have high explanatory power in some periods and return reversal indicators have in other periods. It is also found that the indicator with 
high explanatory power is useful to predict future market prices. Based on these results, we tried to predict future stock prices using the real stock price data in Japan, and gained positive return. Then, we concluded that investors who use technical indicators to estimate future stock prices may influence significantly to the market price creation.

In future works, we would like to treat an impact of price creation by the Meta investor who is assumed not to influence market prices in this paper.

\section{References}

[1] R.J. Shiller, "Do Stock Prices Move too Much to be Justified by Subsequent Changes in

Dividends?," American Economic Review 71, pp. 421-436, 1981.

[2] B. LeBaron, "Agent-based Computational Finance," in L. Tesfatsion, K.L. Judd (eds.) Handbook of Computational Economics, Volume 2: Agent-Based Computational Economics, Elsevier Science B.V., to appear.

[3] J.B. Delong, A. Shleifer, L.H. Summers, R.J. Waldmann, "Noise Trader Risk in Financial Markets," Journal of Political Economy 98, pp. 709-738, 1990.

[4] W.B. Arthur, J.H. Holland, B. LeBaron, R. Palmer, P. Taylor, "Asset Pricing under Endogenous Expectations in an Artificial Stock Market," in W.B. Arthur, S. Durlauf, D. Lane, (eds.) The economy as an evolving complex system II, Addison-Wesley, pp. 15-44, 1997.

[5] W.A. Brock, C.H. Hommes, "Heterogeneous Beliefs and Routes to Chaos in a Simple Asset Pricing Model," Journal of Economic Dynamics and Control 22, pp. 1235-1274, 1998.

[6] R.H. Thaler, E.J. Johnson, "Gambling with the House Money and Trying to Break Even: The Effects of Prior Outcomes on Risky Choice," Management Science 34, pp.643-660, 1990.

[7] B.M. Staw, "Knee-Deep in the Big Muddy: A Study of Escalation Commitment to a Chosen Course of Auction," Organizational Behavior and Human Performance 16, pp. 27-44, 1976.

[8] N. Barberis, M. Huang, T. Santos, "Prospect Theory and Asset Prices," Quarterly Journal of Economics 116, pp.1-53, 2001. 